\title{
Editorial
}

\section{Can it be you that I hear?}

Ben Macpherson and Konstantinos Thomaidis

Love can do strange things, especially to those of a poetic persuasion. Unrequited or otherwise, it can invoke emotional turmoil, obsessiveness and an overactive imagination on the part of the lover concerning the object of their affection. Such a depth of romantic feeling led a lovelorn Thomas Hardy to experience a series of aural apparitions, which he mistakenly understood to be his estranged wife Emma, in his poem 'The Voice' (1914). Echoing an idealized past and reverberating with a guilt-ridden and bittersweet present, this autobiographical work concerns Hardy's remembrance of that 'woman much missed', as he imagines her calling to him. In the first half of the poem, Hardy (2005 [1914]: 1160) hallucinates: 'how you call to me, call to me, / [...] Can it be you that I hear?'

The imagined voice of Emma - promising the romance of their early days together in Boscastle - does not last for long. In a bitter moment of self-awareness, Hardy (2005 [1914]: 1160) asks: 'Or is it only the breeze, in its listlessness[?]' It might have sounded like Emma, but the rustling of the trees proved empty, listless.

This temporal shift between the past and the present - wistful nostalgia and bitter disappointment - invokes two different voices: an auditory ghost of Emma drawn from a psychological and emotional yearning, and an ecological voice - the rushing breeze coursing through the trees. Tellingly, the poem's last lines read: 'Wind oozing thin through the thorn from norward, norward / And the woman calling' (Hardy 2005 [1914]: 1160). Hardy knows it 
is the breeze, but cannot help himself - at the poem's end, Emma is still calling him back to a time he once knew.

Multiple voices overcode each other in this work. It is autobiographical, drawn from Hardy's own experience. It is literary, and utilizes alliteration, assonance, repetition and rhyme to further convey a lyrical longing for his love. His lost hope is heard through hallucination and the acoustics of nature, and shifts instantaneously between past and present in the space of a single line. Yet, the title Hardy gave this work connotes singularity: 'The Voice' - a definite article within which so many incarnations, variations and voices interact. In its use of autobiography, literary devices, psychology and ecology, it is in many ways paradigmatic of the aims and scope of the Journal of Interdisciplinary Voice Studies, exemplifying the complex interactions of interdisciplinarity we seek to encourage, facilitate, curate and explore.

Notably, Hardy's poem straightjackets the multifaceted nature of his text at the service of titular brevity. Yet, we seek no such narrowing of what voice(s) can do, or be; indeed, the title of this journal studiously avoids such a reference to the definite article. Rather, 'voice' is defined here as material (like the thorns oozing as the wind rushed from the north) and metaphoric (hallucinatory, a concept, ineffable, intangible). Voice is seen to create or stir memories, confirm relationships, externalize and internalize their loss, in noise and silence, in reality and imagination. Voice is literary, lived-in, longed-for and ultimately, in the pages of this new journal, a site for plural interaction. In this sense, just as Hardy's titular umbrella oversaw a multiplicity of voices at play, the pages of this journal seek to do the same, demonstrated by the selection of articles, practice-based scholarship and performative material in the following sections. 
In the first of three articles in this inaugural issue, sound and performance studies scholar Marcus Cheng Chye Tan offers a reading of vocality and silence as political agents of dissent and multicultural discourse. Using Georges Bataille's dialectic of civilized speech and silent violence to consider mass media and official reactions to riots by foreign workers in the Little India district of Singapore in December 2013, vocality is considered as a sense of social subjectivity and authority, while silence is constructed as a further form of vocality, rather than purely the absence of self. In his conceptual deployment of these terms to understand the local and global reactions to a specific moment of political activism, Tan invokes Don Ihde to suggest that irrespective of imposed silences, voice always has the power to offer freedom from that which is unuttered - even when impositions threaten that materiality or subjectivity.

From the sonic and phenomenological worlds of political activism in Singapore, Matthew Rowney invites us to traverse the English rural idyll of poet John Clare (17931864). The acoustic ecology of several of Clare's mid-period poems is examined in relation to their evocation of time and place, considering the voices of nature as contained in language, structure and metaphor, in a way similar to Thomas Hardy's words considered at the outset. Just as Hardy's literary devices evoked the voice of Emma, Rowney identifies the sonority of objects and their sense of place and time - capturing the moment the pastoral world of Clare's native Helpstone became challenged by the industrial voices of modernity.

Finally, Jonathan Boddam-Whetham's philosophical discussion of Heideggerian theories of Being finds that the call of the conscience in Heidegger's Being and Time (1927) is a silent voice - one that calls to will and to act. This call - this silent voice - takes the form of one, eleven-word sentence early on in Heidegger's mammoth tract and yet, as BoddamWhetham argues, this voice has the power to ricochet back and forth through the entire text, conditioning our understanding of Being. In this article, Boddam-Whetham applies a sonic interpretation of Heidegger's text to a performance of Ray Lee's Siren from the 'SPILL 
Festival' (2014), demonstrating a performative application of the concepts of vocality and silence, existence and experience at play in Being and Time. In doing so, we may find an intense and lateral connection to the official discourses seen in Little India in Tan's opening contribution to this section of the journal.

In many ways, a suggested connection between philosophical, ecological and political concerns exemplifies the interdisciplinary approaches invited and curated through the pages of this new journal. It is because of the broad church of contributions on offer that the potentially rich interplay of connections and juxtapositions can be explored and facilitated, and as you read in depth about the vocality of political discourse, the acoustic ecology and object-voices in poetry, and the philosophical concepts of voice and subjectivity, we invite you to draw your own connections and conclusions, questions and ideas, and of course, potentially consider ways that you might wish to contribute to future issues. In this respect, the following are just some of the areas we invite for consideration in forthcoming issues:

- Voice as methodology

- Voice and philosophy/critical theory

- The (dis)embodied voice

- The aesthetics of spatiality, silence and sound

- Ventriloquism, object and puppetry

- 'Authenticity', autobiography and/or adaptation

- The speech/song continuum on stage/film/performance/new media

- Digital/electronic media and the voice

- Intercultural aesthetics of vocal practice

- Voice training in conservatoire/Higher Education 
Along with interdisciplinary engagement through conventional scholarly articles, recent conversation among voice scholars and practitioners has seen the questioning of conventional academic formats and their suitability for voice-related research. Gaining dual impetus from academia-wide debates on practices, methodologies and conceptualizations of practice-asresearch, and the emergence of voice studies as a distinctive field of inquiry - with its consequent maturing of new epistemologies - the challenge put forward can be formulaically summarized as follows: is interpretive writing the only way to communicate ideas about voice?

A refreshed interest in experimenting with modes of dissemination has begun to develop in response and it seems appropriate for the Journal for Interdisciplinary Voice Studies to accommodate such endeavours and stimulate further investigation in this area. This desire underscores all contributions and weaves through the published issue, but in order to demarcate a clearer platform for this purpose, we have developed the 'Voicings' section of this journal. 'Voicings' is designed to host practice-based, -driven and/or -inclined contributions. As its title implies, 'Voicings' on the one hand hopes to challenge established hierarchies of the exegetical writing over the practised voice while, on the other, its plural form nods to the need for multiple, alternative, polyphonic encounters with vocality.

In this inaugural issue, 'Voicings' opens with a contribution from one of the foremost voice pedagogues in the United Kingdom and the United States. Kristin Linklater offers a kaleidoscopic set of reflections on the art and craft of voice and speech training. Stemming from five decades of rehearsing, teaching and workshopping, Linklater's text is scaffolded by four terms: Voice, Body, Intellect and Emotion, which form what she has found to be the 'Actor's Quartet'. In line with the aims and scope of this section of the journal, Linklater's writing is experiential and generous in its sharing of professional insights. The second part of this contribution unfolds in the style of voice workshop notes and extends an invitation to 
experience the exercises rather than read about them. Having said that, a list of footnotes points the curious reader in the direction of books and articles that help contextualize or have indeed influenced Linklater's methodology of 'freeing the natural voice'.

Following this, 'Voicings' features an extended interview with Sarah Butcher, one of the founding members of leading headphone theatre company non zero one. The group's projects foreground an interest in particular strategies of immersion in site-specific and participatory contexts. The interview, conducted and introduced by Konstantinos Thomaidis, centres on notions of interaction, instruction through pre-recorded and live audio, and, ultimately, intimacy. The UK-based collective pushes boundaries of sonic immersivity in a way that is simultaneously methodical and playful - and the format attempts to capture this ethos. The first part briefly contextualizes non zero one's work in relation to music and mobility, whereas the interview - accompanied by production photographs - unfolds as a dialogic encounter with the artist. In other words, it is an attempt to listen in and to allow the artist's (reflexive) voice to be heard.

Adding to an illustrious line-up of contributors, artists David Mollin and Salomé Voegelin - also influential writers - present a transcript of their latest sound work During the Night Crops will Still Grow (unless the player sleeps) (2015). In a truly interdisciplinary spirit, the first section stems from a sound recording made by one of the artists while looking at Ed Ruscha's Los Angeles Apartments (2013) at the Basel Kunstmuseum, Switzerland. For the most part, the score is a transcribed discussion between the artist and his blind mother in South Wales, conversing on the catalogue of the exhibition. The written text breaks through given syntactical norms and gestures towards the motions, liberties and contingent energies of live vocal interchange. The score is punctuated with Twitter photos that the artists displayed in a recent exhibition, prompted by the transcript of the discussion. Conceptually 
rigorous and artistically stimulating, this contribution balances between the pedestrian and the artful, the sonic and the visual, the composed and the free-flowing.

Indeed, along with the emphasis on natural voice in Linklater, it is precisely this productive layering of the autobiographical, the spatially situated and the imaginative play with vocality and subject - in the work of Mollin and Voegelin, and non zero one - that might also offer provocation redolent of the multiplicity of voices at play in Hardy's poem of lost love.

This selection, then, represents a first but decisive step. As the journal develops, and in close collaboration with our publishing team at Intellect, our aim is to take full advantage of the opportunities afforded by online and media-based platforms in order to keep exploring alternate, multidisciplinary and ground-breaking 'Voicings'. Already, the online publication of all contributions, including articles, offers the chance to 'open up' the discursive content of the text through hyperlinks to websites and embedded audio files - and we encourage future contributors to also engage with the vocal in this way. Potential contributions to 'Voicings' may include, but are in no way limited to:

- Practitioners' reflections

- Vocal scores and transcripts of music/sound/audio/multimedia artworks

- Annotated interviews

- Photographic essays

- Excerpts of rehearsals, workshops, performances

- Voice essays and blog-style contributions 
- Transcripts of roundtables

- Academic discussions of voice in the form of poetic scripts, libretti, mini lexicons, ethnographic notes

- Voice-related documents and archives

- Extended and/or comparative documentations of exhibitions, conferences, events or performances

A similar concern with capturing the building energy of the field is exhibited in the 'Reviews' section of the journal, skilfully led by our Reviews Editor, Gelsey Bell. Monograph publications on voice used to be rare occasions, but the last decade has witnessed a dramatic change in this scarcely populated landscape. From an interdisciplinary perspective, the rising interest in voice has been met with an unprecedented increase in additions to the existing corpus of works - ranging from monographs and edited collections to exhibition catalogues, annotated scores and intermedia outputs. Given that this is the first academic journal dedicated to the interdisciplinary study of voice, we have decided to review publications from up to five years ago - almost documenting the consolidation of the interdiscipline of voice studies in its making. Our reviewers offer expert and passionate reflections on the published works and the hope is that their responses are not side commentaries but valuable contributions to debates around voice in-and-of-themselves. The very fact that the works discussed in this issue originated in sound studies, actor training, cultural studies, philosophy and performance studies speaks volumes for the need to facilitate the crossing of disciplinary boundaries in voice research. 
We are equally interested in publishing reviews of key events where the practices and ideological underpinnings of voice are intensely deliberated in scholarly circles or presented to the public. Apart from the yearly or biannual meetings of dedicated organizations such as the Voice and Speech Trainers' Association (VASTA), the British Voice Association (BVA), the Pan-European Voice Conference (PEVOC) and the International Centre for Voice (ICV), in the last five years the United Kingdom has, for example, seen the following events specifically dedicated to voice: the Song Stage Screen V: Interdisciplinary Approaches to Voice conference (University of Winchester, 2010); the Classical Training Conference (Royal Shakespeare Company, 2011); the Thinking and Singing conferences (Royal Musical Association, 2012 and 2013); 'The Voice' night of talks, performances and activities (Wellcome Trust, 2013); the Interdisciplinary Studies in the Philosophy and Praxis of Voice symposium (Centre for Interdisciplinary Voice Studies, 2014); The Voice of Training interim event (TaPRA/University of Portsmouth, 2014); and the Voice, Memory, Song symposium (University of Oxford, 2014) - to name but a few. Similar synergies between individual artists and researchers and organizations have been also crystallized in international events, including the 'Acts of Voicing' exhibition (Germany, Hong Kong and South Korea, 201213) or the series of 'Nine Intra-Active Lectures on Voice and Performance' hosted by the University of Gothenburg (2015). We are keen on documenting such voice-focused gatherings and exchanges and in this issue's 'Reviews' section, we are pleased to present a review of yet another seminal event: the Voice Studies Now conference, held earlier this year at UCLA, United States.

It is only evident, then, that voice has decisively returned to the forefront of academic discourses. Needless to say, we are very aware that the remit of a journal can only encompass a certain amount of these reinvigorated efforts. It is our ambition, however, that this new publication will facilitate dialogues and creative cross-fertilizations across hitherto 
demarcated fields of research - and that our understanding, and pleasure, of voice will get all the more nuanced and significantly richer for that.

We hope that you enjoy the first issue of the Journal of Interdisciplinary Voice Studies.

\section{References}

Hardy, T. (2005 [1914]), 'The Voice', in M. Ferguson, M. J. Salter and J. Stallworthy (eds), The Norton Anthology of Poetry (5th Edition), New York/London: W.W. Norton and Company Inc., p. 1160. 